\title{
STUDYING THE CHANGE OF SOIL RESONANCE PROPERTIES DUE TO BURRIED ROOM IN THE SUBSURFACE
}

\author{
Dr. M. A. Gamal Associate Prof.: Geophysics Dept. Faculty of science, Cairo University \\ magamal@sci.cu.edu.eg; Dr. E. Ghoneim Associate Prof.: Civil Eng. dept, \\ Faculty of Eng., Helwan Univ. \& Ali Mekki Teaching assistant, Faculty of Biotechnology, \\ October University of Modern Sciences \& Arts
}

\section{ABSTRACT}

Still the change in soil due making new buildings is not very clear. The present study is giving the light on change of soil due to structures and change of structures due to soil or what is named soil-structure interaction. Rivera City is one of the newly generated cities located in Sheikh Zayd City (Figure 1). The natural frequency of vibration of the soil of Rivera city was determined in relatively remote area using Microtremors technique. It was found to be about 10HZ. The same method was used again for determining the natural frequency of vibration empty room buried under the ground lever which was found to be about $5 \mathrm{HZ}$. The dimension of the buried room is $2.5 \mathrm{~m}$ height, $4.5 \mathrm{~m}$ length and $3 \mathrm{~m}$ width. A dynamic analysis model for this buried room was determined using a structural analysis software ETABS v18.1 and was found to be about $5 \mathrm{HZ}$. To study the soil structure interaction a profile was taken starting from the soil and ending over the buried room. The spectrogram analysis method was introduced. The spectrogram is a continuous recording to the change in frequency with time for this profile showed that soil is carrying several frequencies in our case 5,8,12.5, 17.5 and 25 but when the buried room is initiated its resonance frequency is added to the soil. Moreover, after the room was built the spectrogram over the room is filtering the soil frequencies and absorb only the frequencies related to its dimensions in our case $5 \mathrm{HZ}, 10 \mathrm{HZ}$, and $17.5 \mathrm{HZ}$ and make it continuous and clear. The study suggests that initiation of new constructions affect the soil and introduce new frequencies and also the new buildings make filter to the frequencies carried by the soil and show only frequencies related to its properties.

KEYWORDS: Microtremors, natural frequency, vibration, spectrogram, buried structures

\section{1-INTRODUCTION}

Lots of authors are using the Microtremors now to detect structure responses and its natural frequency of vibration (e.g. Jiang et al, 2016). The natural frequency of vibration of building is a very important factor that governs all calculations concerning seismic codes for buildings. Most codes are based on knowing the natural frequency of vibration of structure (or equivalently the natural period of vibration $\mathrm{T}$ ) to know the deformation response of the structure. It is very difficult to find data concerning the resonance frequencies of vibration of all buildings at any country and especially Egypt. This is due to the lack of such studies not and randomness in building. Knowing the natural frequency of vibration for any building combined with shaking parameter (Disp. Vel. Or Acceleration) during an earthquake, could be used all together to adjust the amount of force that could affect the building base (e.g. base 
shear for or base moment). Unfortunately, there is no accurate building codes are justified for Egypt until now.

Microtremors are omnipresent low amplitude oscillations (1-10 microns) that arise predominantly from oceanic, atmospheric, and cultural disturbances. It may be considered to compose of any of seismic wave types. We have two main types of Microtremors, Local cultural noise coming from urban disturbances and long period Microtremors originated from farther distances (e.g. Oceanic disturbances). Still there is a big contradiction between the correct types of noise that should be used (especially for soil response). While some is dealing with the longer period Microtremors originated from farther distances (oceanographic disturbances) excluding urban excited sites where high degree of local cultural noise exist (e.g. Field et al, 1990), others considered the traffic and cultural noise does not affect Microtremors response. Moreover, they considered the excited soils (sometimes by a helicopter) gives even more convincing site responses. They found good agreement between soil responses excluded from excited soils compared with those derived from strong motion recorded data (Mucciarelli, 1998). Mucciarelli, 1998, made constrictions to Microtremors generated by winds or coming out from asphalt (asphaltic waves) and considered them as false effects and should be removed.

The implicit assumption of early studies was that Microtremors spectra are flat and broadband before they enter the region of interest. When Microtremors enters preferable body it changes and resonate depending on the nature of the material, shape, and any other characteristics of this body. We think that There is no big difference between soil response and building response. The soil response is depending mainly on identifying the resonance of surface layering by dividing the Microtremors response for surface layer by Microtremors response of a nearby deeper bedrock called the "reference site" (outcrop of nearby consolidated sediments or basement rock) this is to maintain the fundamental resonance modes of vibrations for this beds. The reality of method is depending on the phenomenon that when both sites are having the same source of noise then by dividing them the effect of source of noise and path effect will vanish leaving the effect of the site.

Kanai 1957, first introduced the use of Microtremors, or ambient seismic noise, to estimate the earthquake site response (soil amplification). After that lots of people followed this work but from the point of soil amplification of earthquake energy for different frequencies (e.g. Kanai and Tanaka 1961 and Kanai 1962, Kagami et al, 1982 and 1986; Rogers et al., 1984; Lermo et al., 1988; Celebi et al. 1987).

\section{2-INSTRUMENTS AND DATA ACQUISITION}

To record the Microtremors we used mobile ES-3000 Geometrics stations combined with a triaxial geophone of $4.5 \mathrm{HZ}$ (Figure 1). The two horizontal components, one was directed to East-West and the other to North-South in addition to the vertical components. Station ST1 is used to determine the natural frequency of vibration for Rivera City Soil and amplification factor of Rivera City, while profile S1 to S11 was used to re-determine the natural frequency of vibration of the soil and the buried room (Figure $2 \&$ Figure3). 


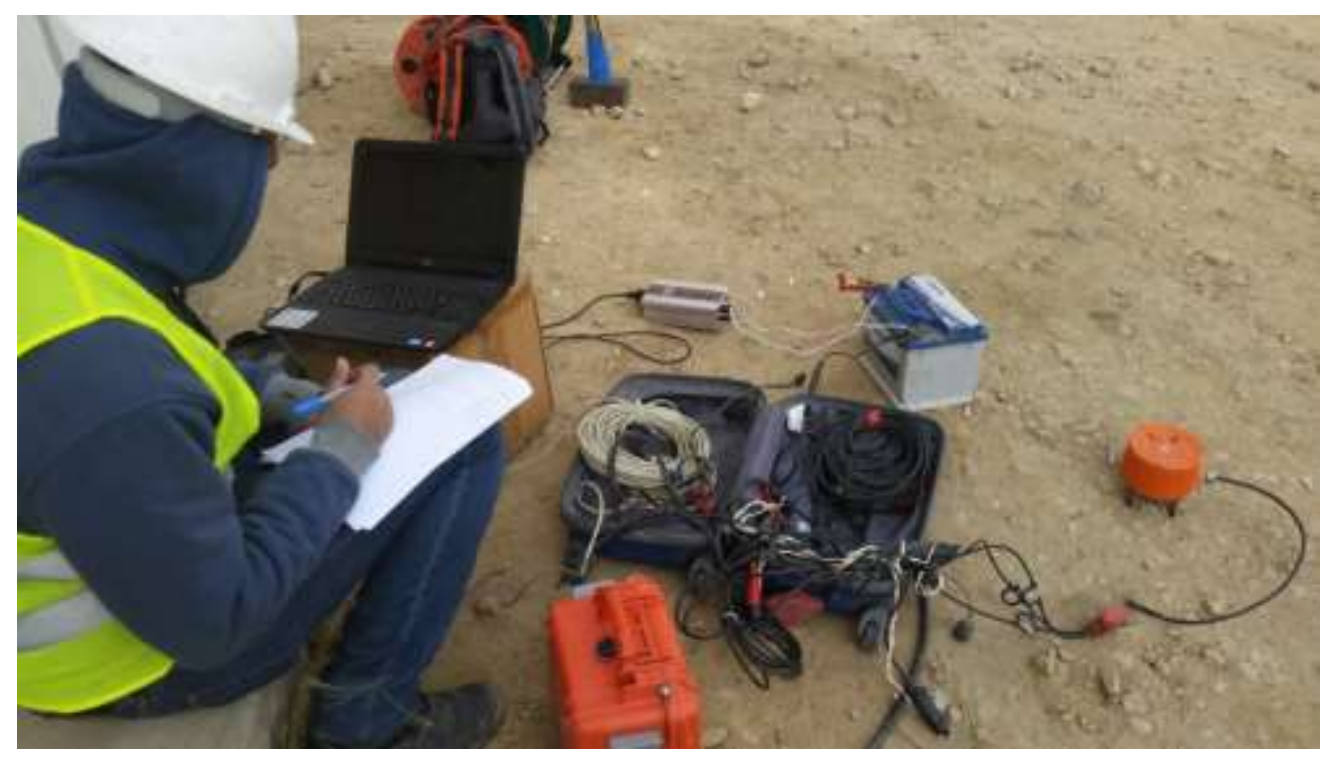

Figure 1: ES-3000 seismograph, Geometrics, USA and Traxial geophone $4.5 \mathrm{HZ}$ used to determine soil amplification at Rivera City.

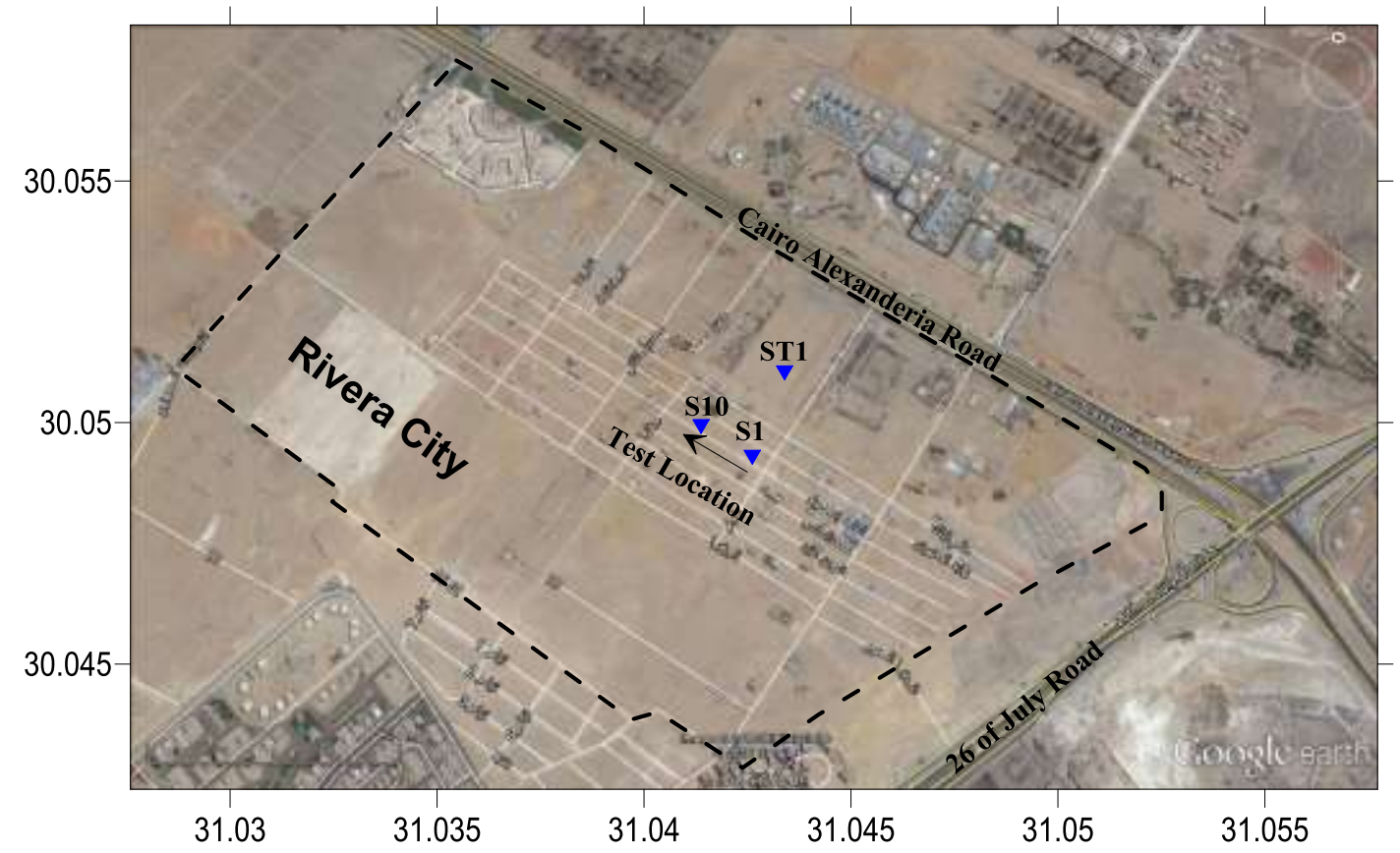

Figure 2: Base map showing the location of soil Microtremors stations ST1 and profile S1 to S10 beside and over the buried room at Rivera City.

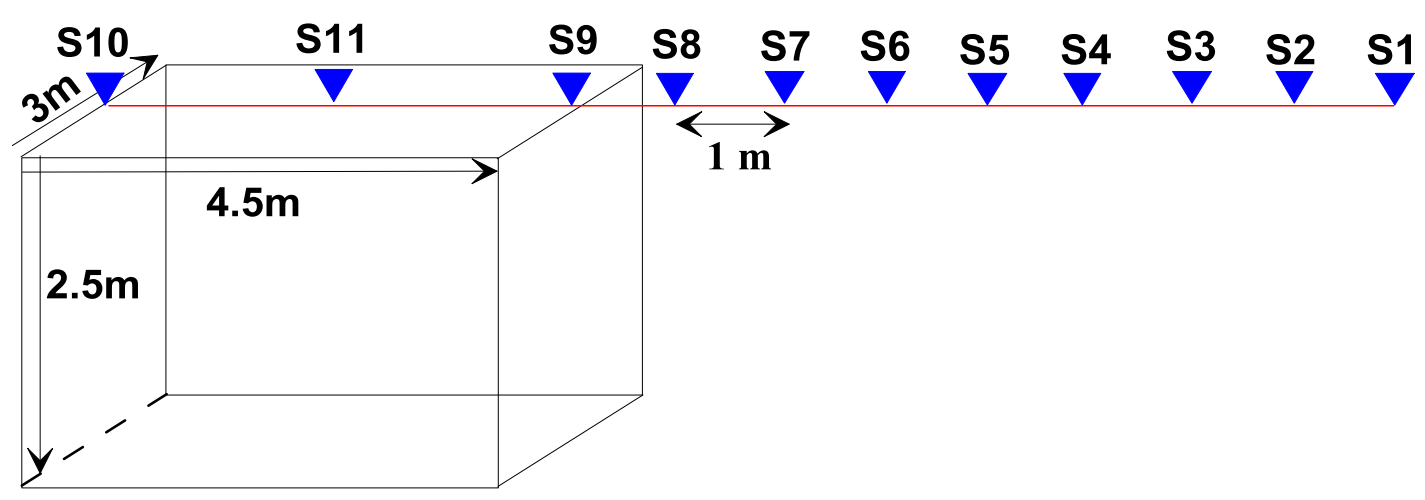


Figure 3: Sketch showing the recorded Microtremors stations over the buried room and its dimensions

\section{3-METHODOLOGY}

We applied these main processing steps when treating the raw data for determining Microtremors soil or structure response:

1- A 300 seconds of Microtremors were recorded at fixed station location,

2- Successful calm stations were used and noisy stations were avoided as possible (Figure 4 \&5)

3-Zero correction to the total 300-min. Microtremors noise at time domain was applied,

4-Each 300-second. was subdivided into several subwindows, which was averaged

5-Site response of a station is derived by applying running average filter window which averaging every 21 points and put it in the center of the window.

7-The soil amplification was derived by dividing the average spectrum by a constant value which constitute the base of the curve (Figure 6)

8- a plan was prepared using AUTOCAD program as a $2 D$ model $4.5 m$ length and $3 m$ width

9- Importing the previous plan to ETABS program in order to add the third dimension (height

$=2.5 \mathrm{~m})$ and also to perform the dynamic analysis

10- Defining and assigning of materials for the room were added into the $3 D$ model

11- Analyzing the building model and checking results

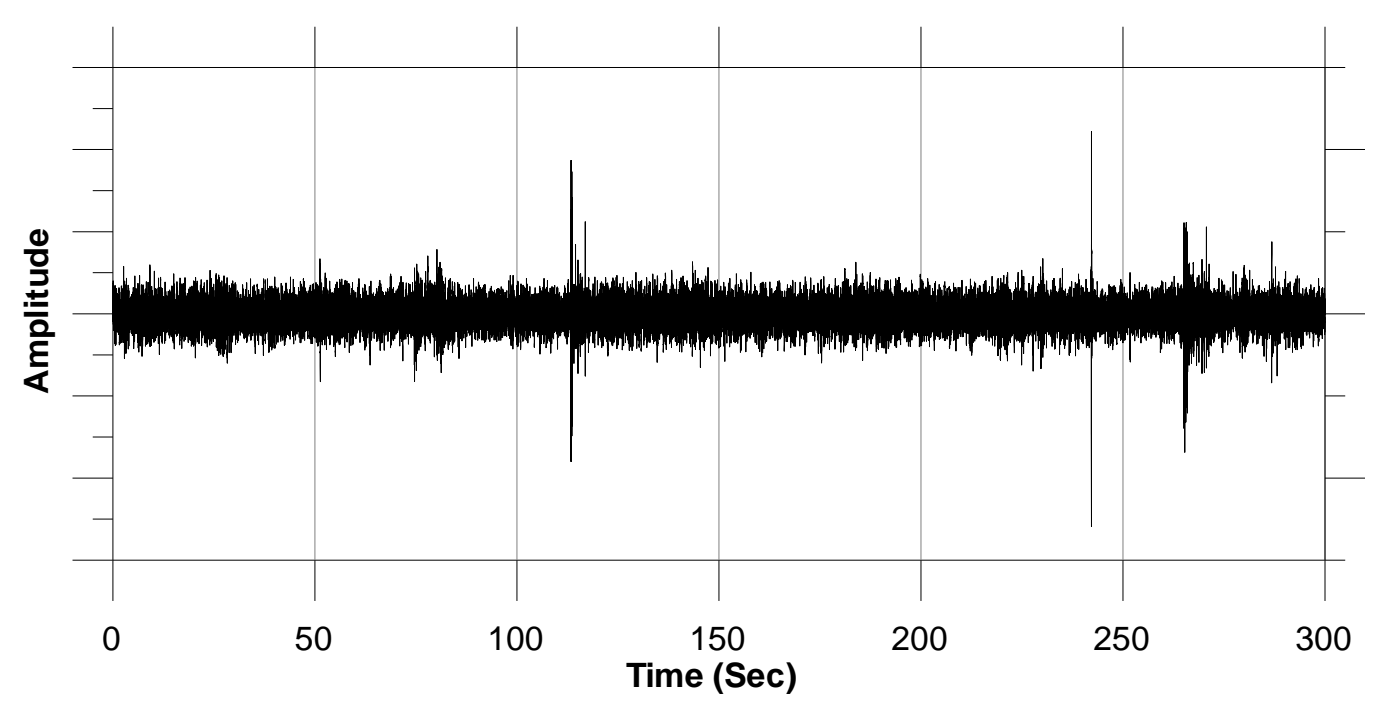

Figure 4: Example of Successfully recorded calm Microtremors station. 


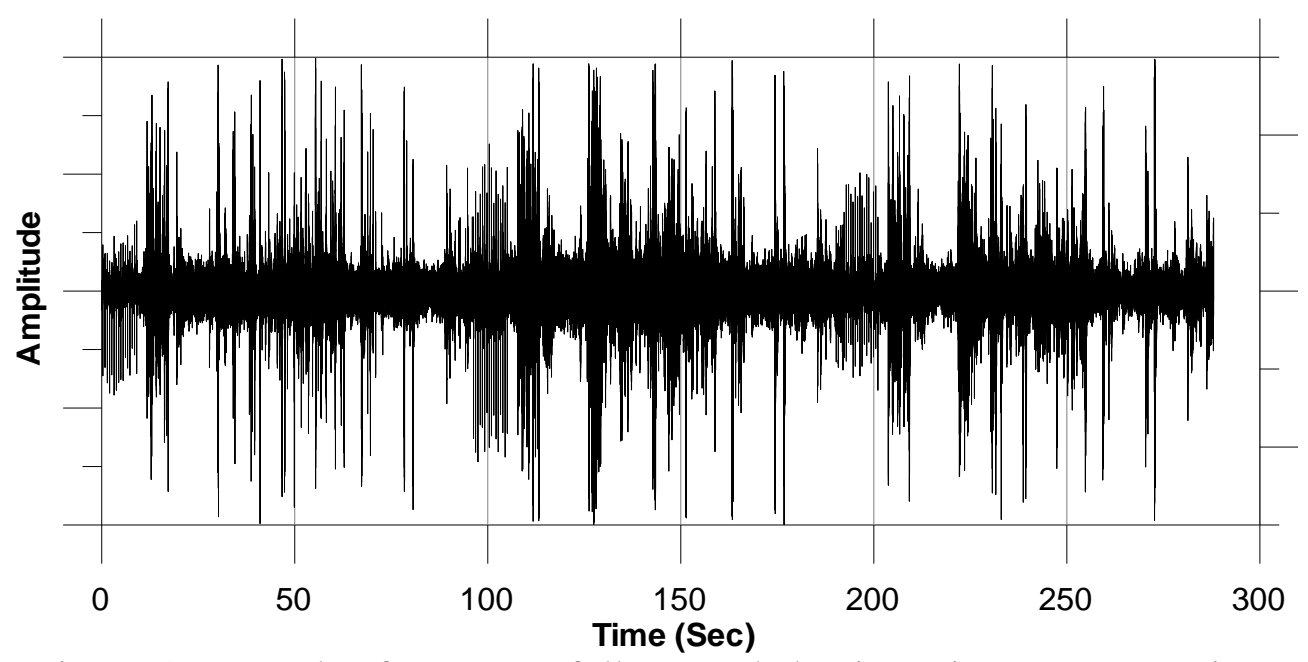

Figure 5: Example of unsuccessfully recorded noisy Microtremors station.

\section{4-LOW FREQUENCY RESULTS (1-10 HZ)}

The above technique is used to determine the Soil natural frequency and amplification factor for Rivera city (Figure 6). The natural frequency of vibration for Rivera City was found to be about $5 \mathrm{HZ}$ with amplification factor 4 . The amplification factor was determined by dividing the value of the spectrum by the value at the base of the spectrum which is touching the base of the curve. This was considered as the calm flat spectrum. It is worth mentioning here that the amplification factor is unrealistically high most probably due to the high level of noises from construction machines working in the time of taking the samples (Figure 5)

Another profile with 11 stations was taken (S1 to S11 Figure3) to determine the change in resonance frequencies for both soil and buried room. As It can be seen the effect of the natural frequency of the soil is bigger in station S1 (Figure $3 \& 7$ ), which is farthest station from the buried room. As we are approaching the center of the buried room the natural frequency of vibration of the room $(\sim 8.5 \mathrm{HZ})$ is increasing in amplitude until it reaches its maximum amplitude at the center of the room at station S11 (Figure 8).

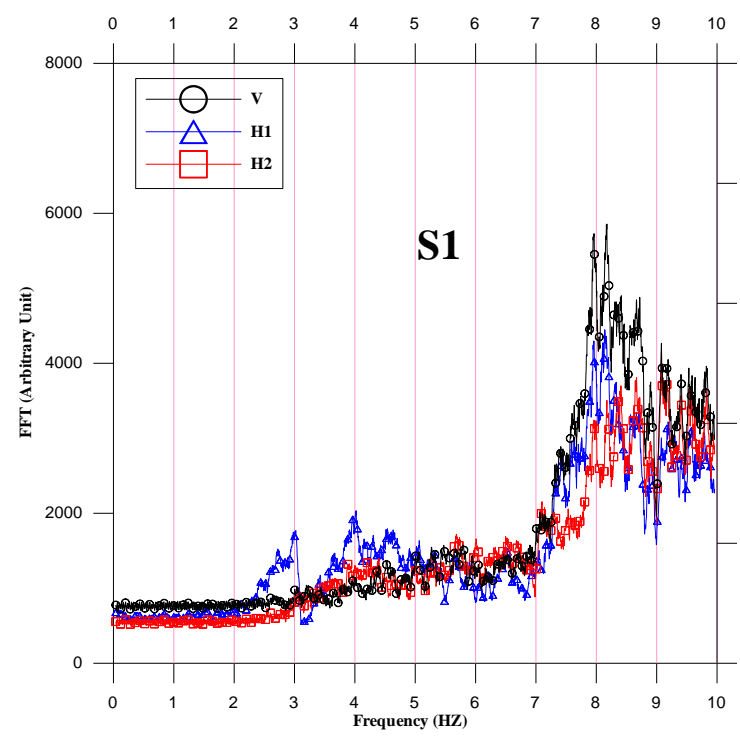




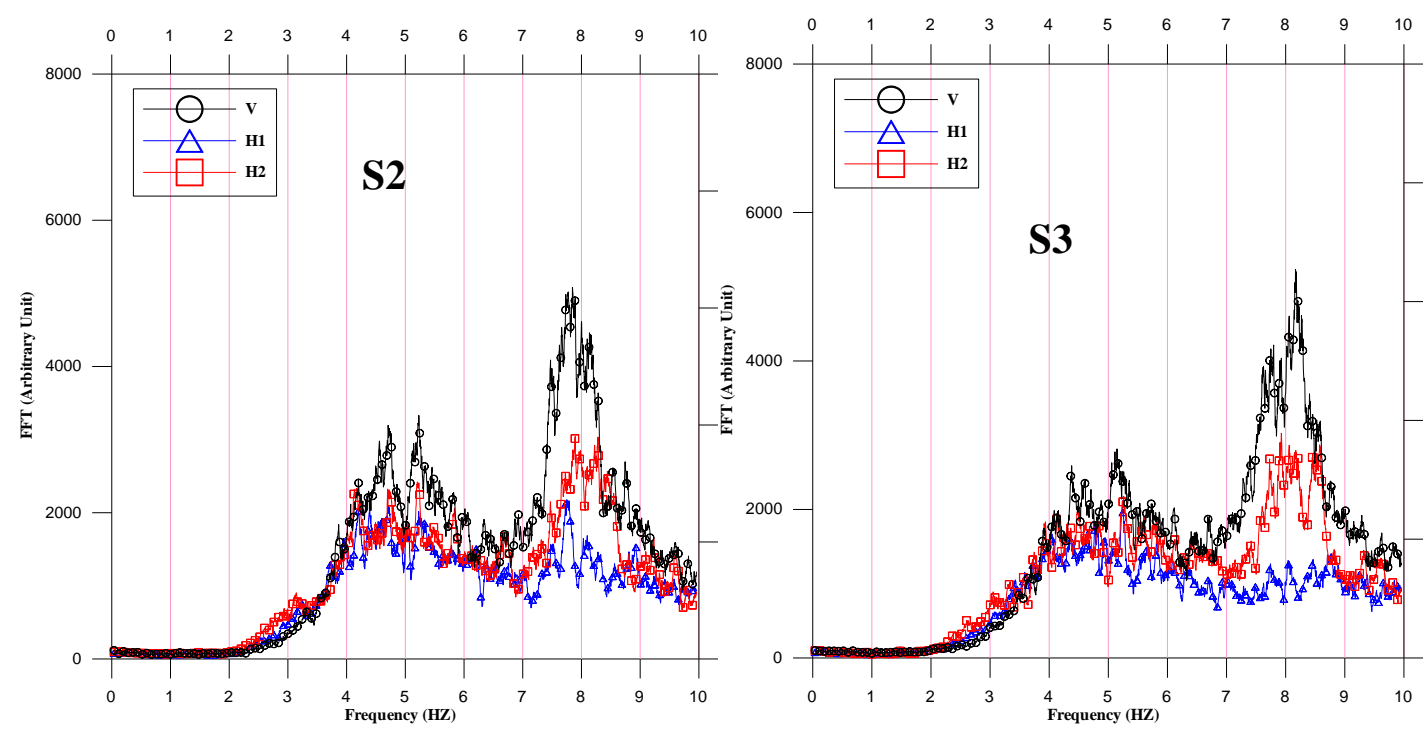

Figure 6: Fourier spectrum for stations ${ }_{9} \mathrm{~S} 1_{1}$ to $\mathrm{S} 3$ recorded ov̧er the şoil ${ }_{6}$ of Rivera ${ }_{9} \mathrm{City}$ showing the frequency of soil $(10 \mathrm{HZ})$ is mixedowith the frequency of the room $(5 \mathrm{~Hz})$ as

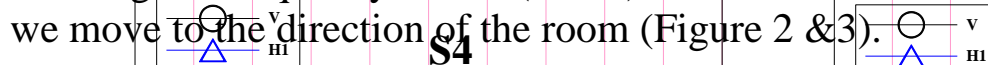

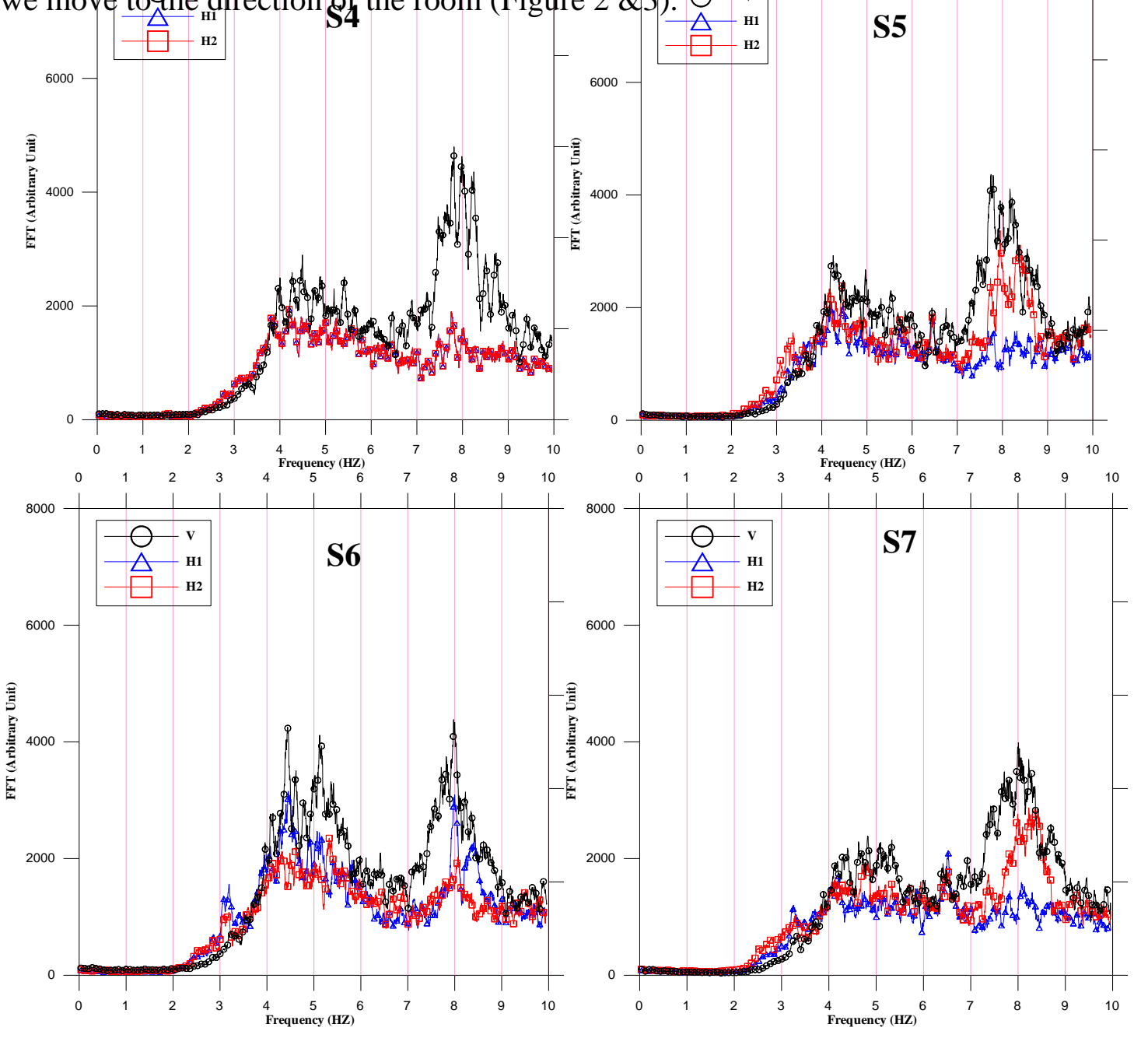



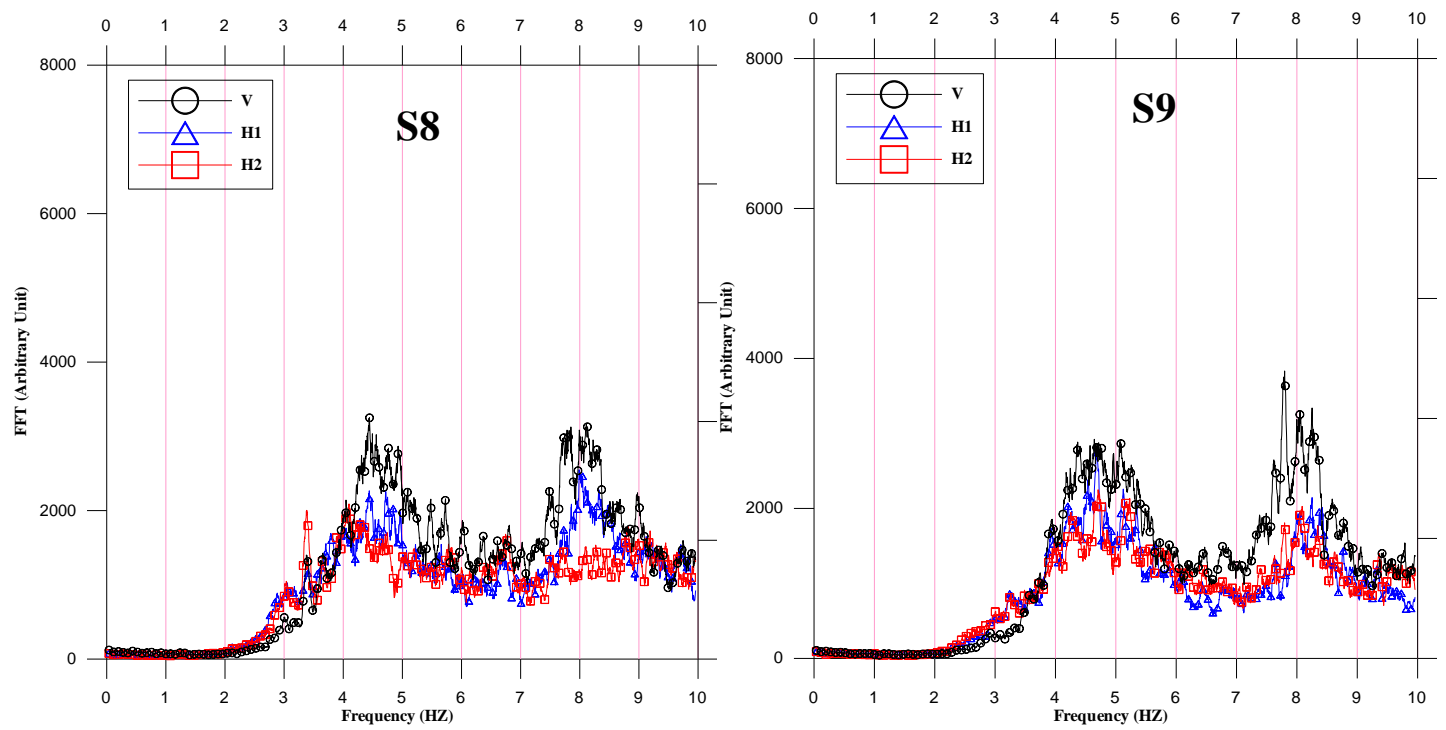

Figure 7: Fourier spectrum for stations S4 to S9 recorded over the soil of Rivera City showing the frequency of soil $(10 \mathrm{HZ})$ is mixed with the frequency of the room $(5 \mathrm{~Hz})$ as

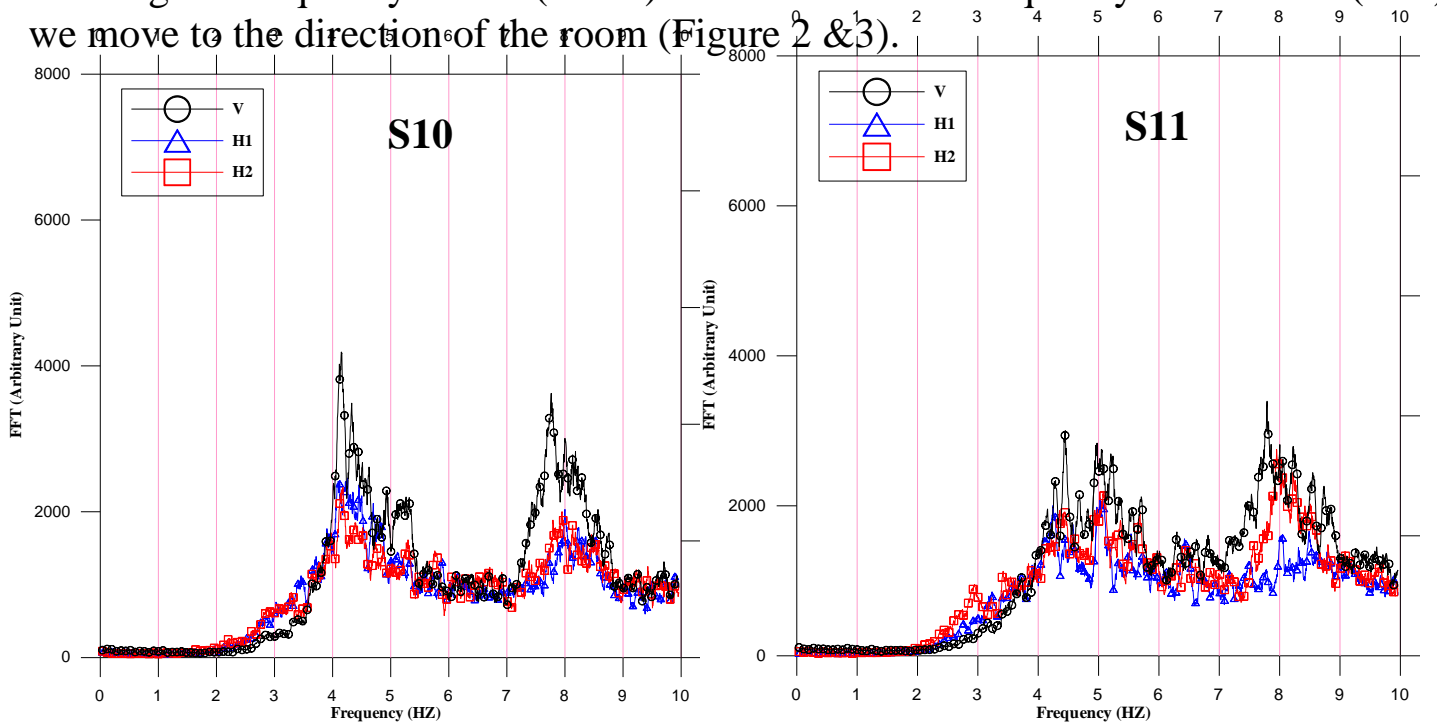

Figure 7: Fourier spectrum for stations S11 \& S12 recorded over the room showing the frequency of soil $(10 \mathrm{HZ})$ is nearly the same as the frequency of the room $(5 \mathrm{~Hz})$ as we are over the room (Figure $2 \& 3$ ).

\section{SPECTROGRAM ANALYSIS:}

Spectrograms are a relation between frequency, time and amplitude. It is being used to look at frequency content of continuous signals recorded by individual or groups of seismometers to help distinguish and characterize different types of vibrations in the earth. Not only we can see whether there is more or less energy at, at certain frequencies, but also, we can see how energy levels vary over time.

We have used the spectrogram analysis here to show how natural frequency of vibrations for both soil and buried room and also power are changed while moving from the soil into the buried room (figure 2). 
Only 4 minutes were enough to show what is happening. The Calculated spectrogram over at the location of ST1 is representing the soil (Figure $3 \& 9$ ) is showing lots of frequencies 12.5, 17.5 and $25 \mathrm{HZ}$.

While the spectrogram taken over the center of the buried room at the location of ST11 (Figure 3), is filtering these frequencies to only three 5HZ, 8HZ and $17.5 \mathrm{HZ}$.

It is also noted that frequencies are taking like energy levels. These levels are continuous in the buried room and clear (Figure 10), while it is faint, weak and not continuous in the soil (Figure 9). This is most probably due to the fact that the soil is full of lots of resonance frequencies coming from different buildings and other sources. While the structures are filtering these frequencies and take only the frequencies related to its dimensions, stiffness, mass and other structural properties.

\section{6-DETERMING THE NATURAL FREQUENCY OF THE VIBRATION OF THE BURRIED ROOM USING SIMULATION PROGRAMS:}

To achieve the objectives of the study that is to analyze and design commercial building using ETABS, which meets the basic requirements such as safety, durability, it has been proposed to follow the following methodology. The structural plan is prepared using AUTOCAD. The center line diagram is prepared and imported to ETABS model, and the following step by step procedures are followed:

- Soil investigation

- Structural analysis

- Design and analysis in ETABS

The engineering properties of soil like water content and density are calculated by conducting tests in laboratory. The structural plan is prepared using AUTOCAD. The center line diagram is prepared and imported to ETAB model, and the following step by step procedures are followed: 


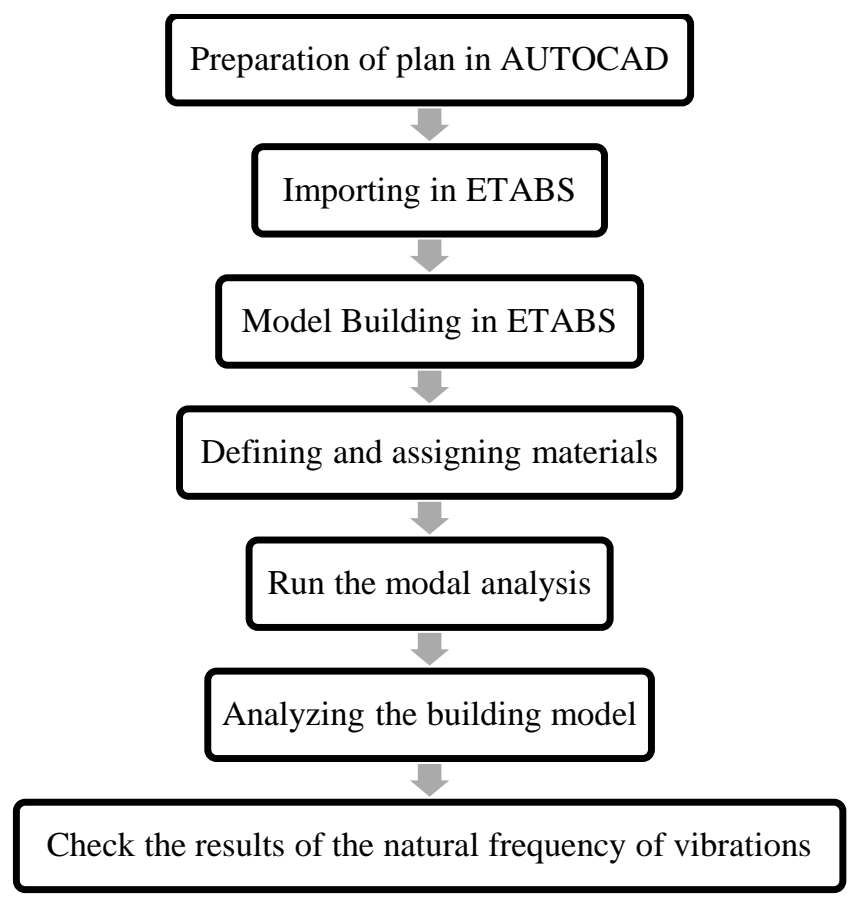

Step - 1: Defining of property

Slab: Slab Thickness $=25 \mathrm{~cm}$

Walls: Walls Thickness $=25 \mathrm{~cm}$

Step - 2: Assigning of Property

Step - 3: Defining of loads

Deadload $=2.6 \mathrm{KN} / \mathrm{m}^{2}$

Live load $=0 \mathrm{KN} / \mathrm{m}^{2}$

Floor finishers $=1.0 \mathrm{KN} / \mathrm{m}^{2}$

Step - 4: Run the Modal analysis

Modal case sub type: Eigen

P-Delta: Noniterative based on mass

Step - 5: Analysis-After the completion of all the above steps and extract the frequency table after running the model analysis to check the natural frequency of vibration for each mode as shown in table (1) 


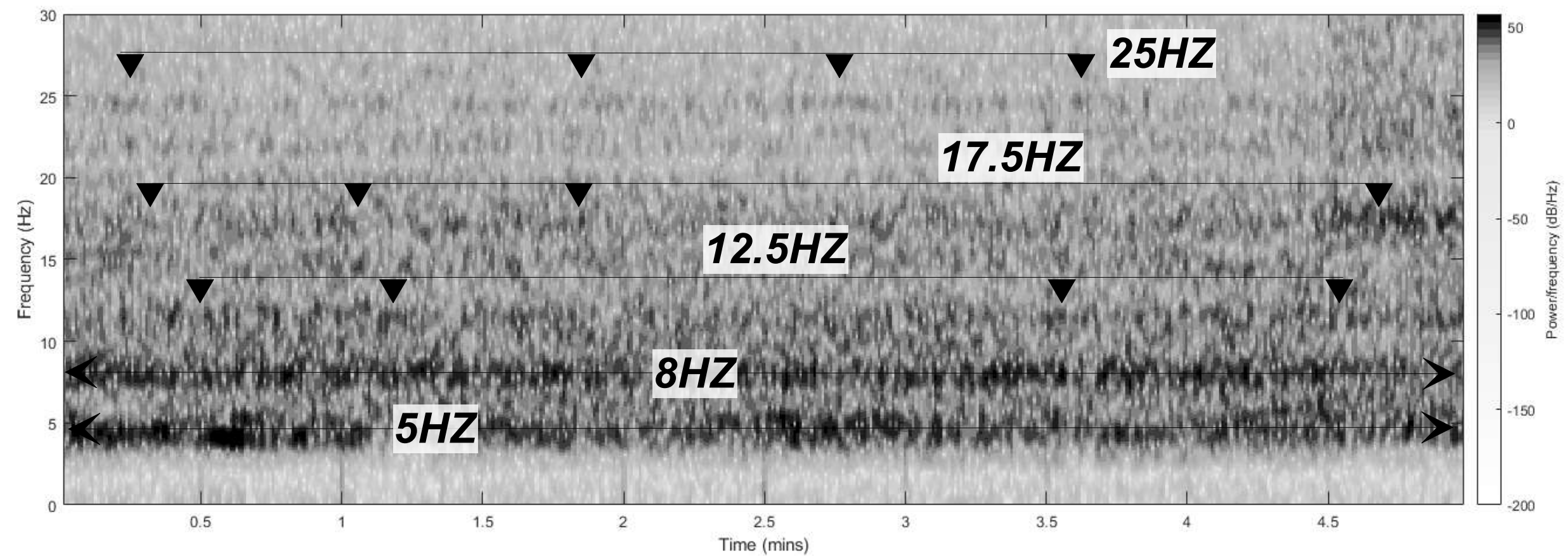

Figure 9: Calculated spectrogram for soil station S1, showing the two main frequencies $5 \mathrm{HZ}, 10 \mathrm{HZ}$ and some other resonance frequencies such as $12.5,17.5$ and $25 \mathrm{HZ}$. 


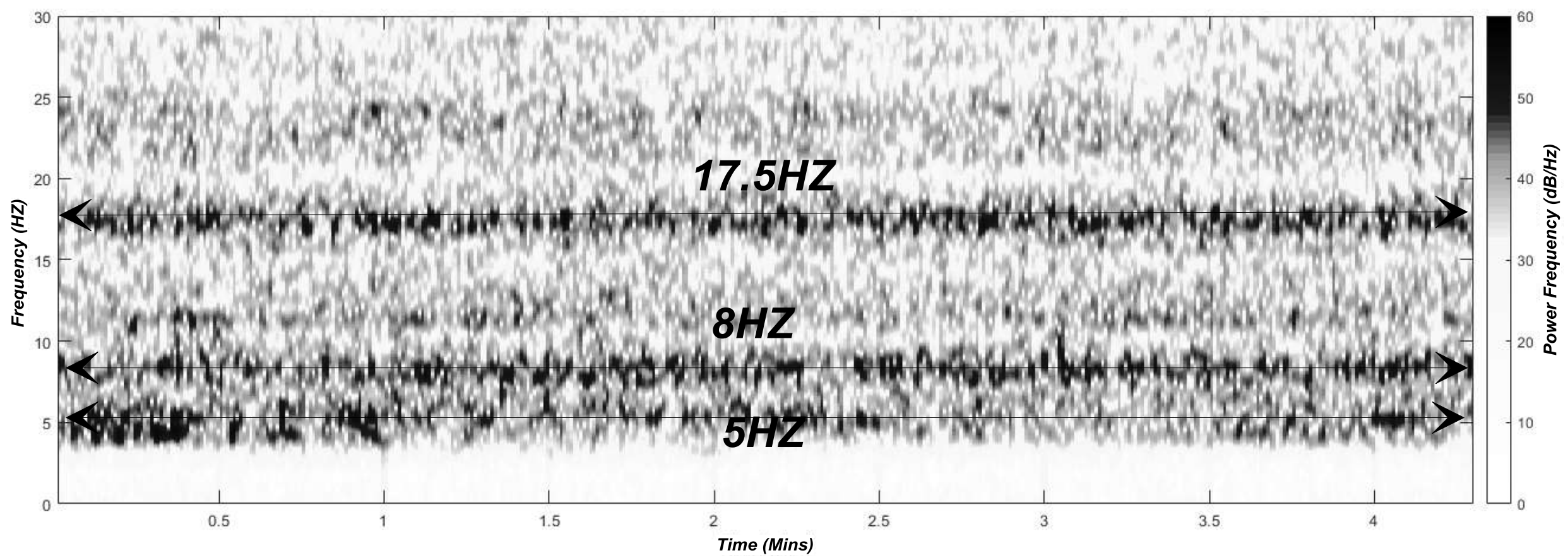

Figure 10: Calculated spectrogram $(0-30 \mathrm{HZ})$ for station S11 over the buried room, showing resonance frequencies of $5 \mathrm{HZ}, 8 \mathrm{HZ}$ and $17.5 \mathrm{HZ}$ most probably due to its structural nature. 
Table (1): Modal Periods And Frequencies of the buried room

\begin{tabular}{|c|c|c|c|c|c|c|}
\hline & & & & & & $\begin{array}{l}\text { TABLE: Mod } \\
\text { OutputCase }\end{array}$ \\
\hline Eigenvalue & CircFreq & Frequency & Period & StepNum & StepType & \\
\hline $\mathrm{rad} 2 / \mathrm{sec} 2$ & $\mathrm{rad} / \mathrm{sec}$ & Cyc/sec & $\mathrm{Sec}$ & Unitless & Text & Text \\
\hline 1222.411901 & 34.96300761 & 5.564535486 & 0.17971 & & Mode & MODAL \\
\hline 1259.029202 & 35,4828015 & 5.647263253 & 0.177077 & & Mode & MODAL \\
\hline 1459.981399 & 38.20970294 & 6.081263097 & 0.16444 & & Mode & MODAL \\
\hline 1864.729214 & 43.18251051 & 6.872710003 & 0.145503 & & Mode & MODAL \\
\hline 2446.393742 & 49.46103256 & 7.871967823 & 0.127033 & & Mode & MODAL \\
\hline 2698.002596 & 51.94230064 & 8.266873903 & 0.120965 & & Mode & MODAL \\
\hline 590664.2146 & 768.5468201 & 122.3180254 & 0.008175 & & Mode & MODAL \\
\hline 1084150.274 & 1041.225371 & 165.7161647 & 0.006034 & & Mode & MODAL \\
\hline 1084431.505 & 1041.360411 & 165.7376569 & 0.006034 & & Mode & MODAL \\
\hline 1417720.276 & 1190.680594 & 189.5027021 & 0.005277 & & Mode & MODAL \\
\hline 1663102.931 & 1289.613481 & 205.2483602 & 0.004872 & & Mode & MODAL \\
\hline 1704720.464 & 1305.649441 & 207.8005626 & 0.004812 & & Mode & MODAL \\
\hline
\end{tabular}

\section{9-CONCLUSIONS}

Microtremors proved to be one of the best ways capable to identify experimentally the fundamental modes of vibration for soil and buried structures. The Natural frequency of vibration of Rivera City is found to be $5 \mathrm{HZ}$ and amplification factor of about 1.5 times. Hence this soil is not suitable for short buildings $\leq 7$ floor of similar fundamental frequency of vibration, to avoid building resonance in earthquake energy excitation.

For the first time Noise was used to identify the natural frequency of vibration of buried structures. The comparison between simple empirical relations, complex 3-D structural programs and Microtremors gave credit to Microtremors as simple, as un accurate way to determine the natural frequency of vibration of buried structures. This can be used later to identify the dimension of buried structures such as Cavities, Rooms, tunnels or any other buried structures.

The natural frequency of vibration for Rivera city soil amplification was determined using Microtremors technique. The advanced 3-d structural simulation programs are more reliable than the traditional empirical equations used to calculate the natural frequencies of vibration. A better way is to use excitation force that is similar to shear forces carried by earthquakes and record this shaking by building a seismographs or accelerometers stations built in inside the structure to try to find its response during vibration. This is considered to be the bestknown realistic method tell know. However, limitation for this method is coming from the fact that no source is big enough to simulate seismic energy emerging from an earthquake. Microtremors method is a new technique resembles this last method, except it used noise instead of earthquake or big excitation Energy.

Instead of using a big seismic source capable of emigrating P-Waves and S-Waves we took benefits from another source of vibration that enters almost all things on earth which is NOISE or the so called MICROTREMORS. Both Microtremors and 3D simulation programs methods were used to determine the natural frequency of vibration of the buried room for double-check of its resonance frequency. The artificial room was buried under Rivera soil at $1 \mathrm{~m}$ depth and have dimensions of $2.5 \mathrm{~m}$ height, $4.5 \mathrm{~m}$ length and $3 \mathrm{~m}$ width Figure 2. 
The room building plans has been drawn in AUTOCAD software and designed for Walls and Slabs. The dead load, live load. The results obtained are safe from manual calculations and software results. By using ETABS, the analysis and design work we can tell that both methods from microtremors that presented as a frequency curves or spectrograms and ETABS software are giving a very near results of natural frequency of vibrations that varies from $5 \mathrm{HZ}$ $\approx 5.5 \mathrm{HZ}$

\section{REFERENCES}

Bhandarkar,R., Ratanpara, M.,\& Qureshi,M.(2017).Seismic Analysis \& Design of Multistory Building Using Etabs.IJIERT,5(2),78-90. ISSN: 2321-9939.

Bhargavi, V., \& Devi, M. (2020). Analysis of Outrigger Structural System for High-Rise Building Subjected to Earthquake Loads. IJIERT, 7(8),20-32. ISSN: 2394-3696.

Castro, R. R., F. Pacor, A. Sala, and C. Petrungaro (1996). S Wave attenuation and site effects in the region of Friull, Italy, J. Geophysics. Res. 101, 22355-22369.

Celebi, M., C. Dietel, J. Prince, M. Onate, and G. Chavez (1987). Site amplification in Mexico City (determined from 19 September 1985 strong-motion records and from records of weak motion), in Ground Motion and Engineering Seismology, A. S. Cakmak (Editor), Alsevier, Amsterdam, 141-152.

Chandrasekhar, R., \& Kumar, L. (2019). Seismic Analysis of High-Rise Buildings (G+30) by Using ETABS. IJTIMES, 5(3),174-181. e-ISSN: 2455-2585.

Chopra, A. K. (1981). Dynamics of structures, a primer Earthquake engineering research institute.

Chopra, A. K., (1995). "Dynamic of structures - Theory and Application to Earthquake Engineering, Englewood Cliffs, New Jersey.

Egyptian Code. Egyptian code of Practice (ECP -1993) for estimating loads and forces, 1993. F. Nateghi-A, (1994). Seismic strengthening of a ten story steel framed hospital: Earthquake resistant Construction \& design, Savidis (ed.), Balkema, Rotterdam, ISBN 905410392 2, P 849-856.

Field E. H., S. E. Hough, and . H. Jacob (1990). Using Microtremors to assess potential earthquake site response, a case study in Flushing Meadows, New york city. Bulletin of the Society of America, Vol. 80. No. 6, pp. 1456-1480, December, 1990.

Gamal , M. A., (2001). Seismic hazard analysis of Egypt and seismic Microzonation of the Greater Cairo based on empirical and theoretical models. Ph.D. Faculty of science, Geophysics dept., Cairo university, Egypt.

Goud, P., Anusha,B.,Raghavendra, B., Shashipreetham,K.,\& Sai Krishna, M. (2020). Analysis and Design of Hostel Building(G+4) using Etabs. IJEAST,4(12),211-214. ISSN:2455-2143.

Jose, R. , Mathew, R., Devan, S. , Venu, S. ,\& Mohith, Y. (2017). Analysis and Design of Commercial Building using Etabs. IRJET,4(6),625-630. e-ISSN: 2395 -0056.

Kagami, H., C. M. Duke, G. C. Liang, and Y. Ohta (1982). Observation of 1-5 second Microtremors and their application to earthquake engineering. Part II. Evaluation of site effect uppon seismic wave amplification due to extremely deep soils., Bull. Seism. Soc Am. 72, 987-998.

Kagami, H., S. Okada, K. Shiono, M. Oner, M. Dravinski, and A.K. Mal (1986). Observation of 1-5 seconds Microtremors and their application to earthquake engineering. 
Part III. A two-dimensional of the site effect in San Fernando valley, Bull. Seism. Soc. Am. 76, 1801-1812.

Kanai, K. (1957). The requisite conditions for predominant vibration of ground, Bull. Earthq. Res. Inst., Tokyo University, 31, 457.

Kanai, K. (1962). On the spectrum of strong earthquake motions, Primeras J. Argentinas Ing. Antisismica 24, 1.

Kanai, K. and Tanaka (1961). On Microtremors. VII, Bull. Earthq. Res. Inst., Tokyo Univ., 39, 97-115.

Kumar, A., \& Kushwaha,N.(2020). A Review Paper on Progressive Collapse Assessment of Asymmetric High-Rise Building and it's Modelling using ETABS Software. IJIERT,8(9),6873. ISSN: 2321-9653.

Langston, C. A. (1977). Corvallis, Oregon, Crustal and upper mantle receiver structure from teleseismic P and S waves, Bull. Seism. Soc. Am. 67, 713-724.

Lermo, J. and F. J. Chavez-Garcia, (1993). Site effect evaluation using spectral ratios with only one station, Bull. Seism. Soc. Am. 83, 1574-1594.

Lermo, J., M. Rodriguez, and S. K. Singh (1988). The Mexico Earthquake of September 19, 1985: Natural periods of sites in the valley of mexico from Microtremors measurments and from strong motion data, Earthquake Spectra 4, 805-814.

Mucciarelli M., (1998). Reliability and applicability of Nakamura's technique using Microtremors: an experimental approach, Journal of Earthquake Engineering, Vol.2, No.4 625-638 Imperial college press.

Nakamura, Y. (1989). A method for dynamic characteristic estimation of subsurface using microtremor on the ground surface. Q. R. Railway tech. Res. Inst. Rept. 30, 25-33.

Nogoshi, M. and T. Igarashi (1970). On the propagation characteristics of Microtremors, J. Seism. Soc. Jpn. 23, 264-280.

Rinkesh R Bhandarkar,Utsav M Ratanpara ,Mohammed Qureshi, (2017). "Seismic Analysis \& Design of Multistory Building Using Etabs", International Journal of Engineering Development and Research (IJEDR), ISSN:2321-9939, Vol.5, Issue 3, pp.78-90

Rogers, A. M., R. D. Borcherdt, P. A. Covington, and D. M. Perkins (1984). A comparative ground response study near Los Angeles using recordings of Nevada nuclear tests and the 1971 San Fernando earthquake, Bull. Seism. Soc. Am. 74, 1925-1949.

Shukla,R.,\& Saha,P. (2017). Comparative study of a G+10 storied building using ETABS and STAAD. IJIERT, 3(6),108-112. ISSN: 2395-6011.

Uniform Building Code ( UBC,1985 ). International Conference of building officials whittier, California.

Varikuppala, K.,Chandrasekhar, R.,\& Rajashekar. (2015). Analysis and Design of Multi Storied Building by Using Etabs Software. International Journal of Scientific Research,4(7). ISSN:2277 - 8179.

Wilson, E.L, and Habiballah, A (1990). "SAP2000, Structural Analysis Programe" computer and structures Inc., Berkeley, California.

Yujing Jiang, Yang Gao and Xuezhen Wu (2016). The nature frequency identification of tunnel lining based on the microtremor method, Underground Space, Pages 108-113 